\title{
The many faces of transformation
}

Published at www.cmaj.ca on Aug. 24

$\mathrm{T}$ he contrast is nothing short of startling. For years, annual general meetings of the Canadian Medical Association (CMA) were primarily marked by the frequency with which delegates leapt to their feet to extol the virtues of privatization of health care.

But as of the second day of the CMA's 143rd annual gathering, being held in Niagara Falls, Ontario, there's been nary a complaint from the microphones about the inadequacy of pay cheques, prompting many to wonder if CMA proposals to transform Canada's health care system haven't affected an equally remarkable change: transformation of the association itself.

No one has been fooled into thinking that demands for wage increases will end, but so pronounced is the change that Ontario Minister of Health and Long-Term Care Deb Matthews even felt compelled, in a morning address, to commend the association for crafting the transformation document (www .cma.ca/multimedia/CMA/Content_Ima ges/Inside_cma/Advocacy/HCT/HCT-2 010report_en.pdf).

"It is a remarkable and refreshing change of tone, when the CMA, the medical profession, is now turning its attention to what do we need to do together," said Matthews, adding in a tone of near incredulity, that the CMA has crafted "a vision for the future."

It was "particularly refreshing" to get something other than wage demands from a professional medical association, Matthews later told reporters.

The CMA's framework blueprint is structured around proposals for action in five "pillar" areas: "building a culture of patient-centred care; incentives for enhancing access and improving quality of care; enhancing patient access along the continuum of care; helping providers help patients; and building accountability/responsibility at all levels."

What is immediately evident therein

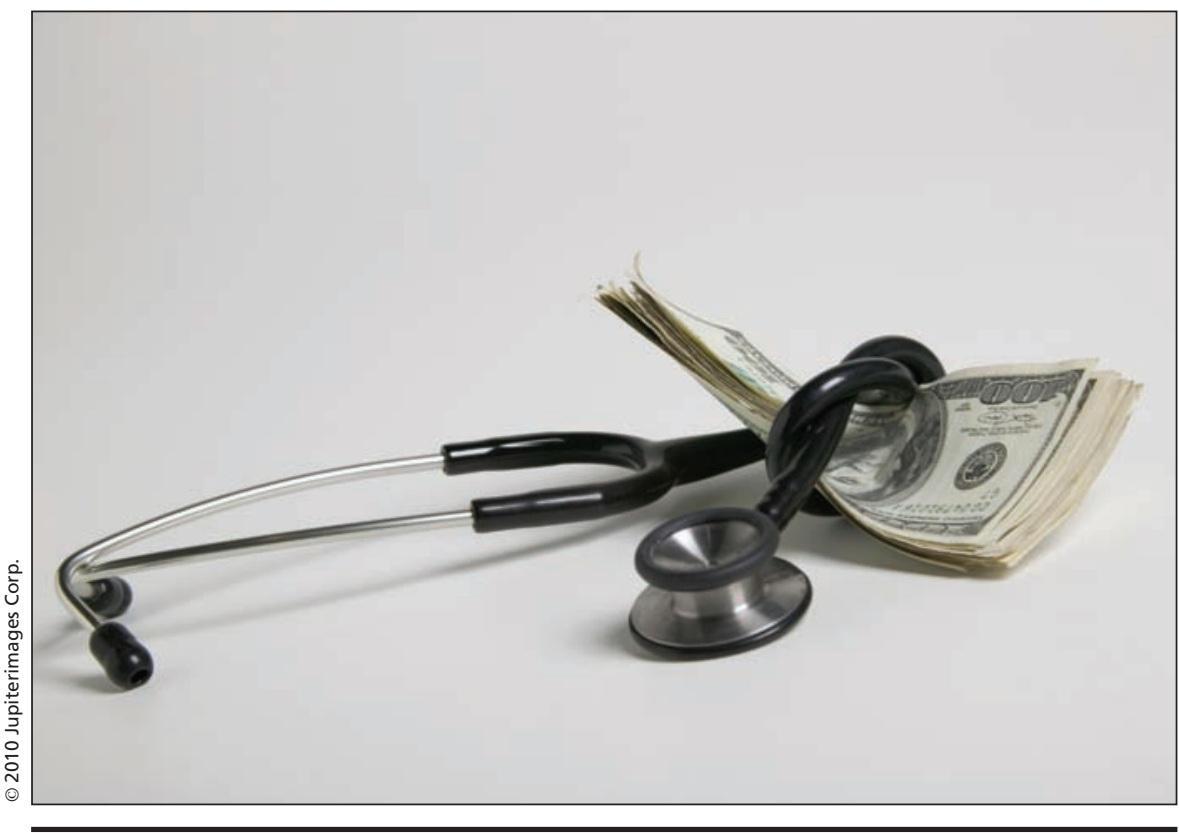

It was "particularly refreshing" to get something other than wage demands from a professional medical association, Ontario Minister of Health and Long-Term Care Deb Matthews said at the CMA's 143rd annual gathering.

is that the ambit of CMA's "transformation" agenda has been significantly expanded beyond anything conceived by its initial proponents, who viewed it largely as a strategy to introduce marketdriven forces in the Canadian health care system (www.cmaj.ca/cgi/doi/10.1503 /cmaj.109-3024).

CMA senior officials say privately that the expansion was largely a function of a belief that the association would have shot its credibility and sacrificed its relevance within the forthcoming decade had it continued along a path of serving primarily as a de facto lobbyist for provincial medical associations involved in contract negotiations with the provinces.

In crafting the blueprint, the senior leadership of the association - the board of governors chaired by Dr. Michael Golbey, incoming President Dr. Jeff Turnbull, current President Dr. Anne Doig and Secretary-General Paul-Emile Cloutier - discovered that transformation of the association was a prerequisite to transformation of the health care system, if the CMA was to be viewed a credible champion of change, one official said.

That appears to sit well with those who viewed the CMA as having been essentially co-opted in recent years by advocates for privatization.

It's reassuring to learn that a professional association can actually begin to represent the views of the majority of its members, says Dr. Danielle Martin, chair of Canadian Doctors for Medicare. "Many CMA members are relieved to see this shift in the organization."

"But I don't think it's a transformation of the profession at all. The profession is where it has always been," she adds. "Every time the CMA polls the profession, they get the same answer, which is that, by and large, its members want to go to work every day and not think too much about these policy issues. But they want to be working in a publicly funded system."

"The number of physicians who are interested in working in private- 
for-profit environments is minute," Martin says. "There were a couple of years where we had a very few of those docs in charge of the CMA and so the association drifted away from its roots."

Martin surmises that part of the reason CMA appears to be retreating from privatization is that it got "push back" from both its members and the general public.

Not that the internal pressure from some doctors for privatization will ever disappear, she adds. "It would be irresponsible not to be skeptical or not to be vigilant" about CMA's blueprint for change. "As soon you become complacent and assume that the association is going to look out for patients and that's it, you risk getting people with other agendas again coming to the fore."

Cloutier earlier told delegates that in the course of developing a new strategic plan to govern association operations over the next five years, many of CMA's strengths and weaknesses became obvious.

The latter included a lack of focus because "CMA tries to do too many things - in other words, we try to be all things for all people," he said.

"As an organization, the CMA is a touch too conservative and too reluctant to innovate," he added. "The organizational structure is a bit too bureaucratic. Finally, and very importantly, member awareness of products and ser- vices available through the CMA is a bit limited."

The ongoing strategic review of CMA operations has pointed to a need to "re-energize the CMA," including its relationship with provincial and territorial medical associations, which will be made "deeper, more effective, more strategic and more rewarding for all parties," Cloutier said.

"I must say, I think it is especially fitting to be engaged in the transformation of the CMA, while we are developing policies for the transformation of health care in Canada," Cloutier added. "As the old saying goes, "the only constant is change'." - Wayne Kondro, CMAJ

DOI:10.1503/cmaj.109-3349 